\title{
Ionic Surfactant Enhancement of Clay Properties for Heavy Metals Adsorption: Kinetics and Isotherms
}

\author{
Adekeye Damilola Kayode ${ }^{1^{*}}$, Asaolu Samuel Sunday ${ }^{1}$, Adefemi Samuel Oluyemi ${ }^{1}$, Ibigbami Olayinka \\ Abidemi $^{1}$, Akinsola Abiodun Folasade ${ }^{2}$, Awoniyi Marcus Gbolahan ${ }^{3}$, and Popoola Olugbenga Kayode ${ }^{1}$ \\ ${ }^{1}$ Department of Chemistry, Ekiti State University, Ado-Ekiti, Nigeria \\ ${ }^{2}$ Department of Industrial Chemistry, Ekiti State University, Ado-Ekiti, Nigeria \\ ${ }^{3}$ Department of Biosciences, University of Nottingham, Nottingham, United Kingdom
}

\section{* Corresponding author:}

email:damilola293@gmail.com

Received: September 4, 2020

Accepted: March 19, 2021

DOI: $10.22146 / \mathrm{ijc} .59480$

\begin{abstract}
The global health problems arising from ingesting toxic metals necessitate the quest for developing efficient materials for their remediation. Surface properties of raw kaolinite clay collected from Ire-Ekiti, South-western Nigeria, were improved by modification using sodium dodecyl sulphate (SDS) for the adsorptive removal of $\mathrm{Pb}, \mathrm{Cr}$, $\mathrm{Ni}$ and $\mathrm{Cu}$ from their respective aqueous solution. The raw and modified clays were characterized by X-ray fluorescence, Fourier transformed infrared spectrometry, Scanning electron microscope coupled with EDX and Particle induced $x$-ray emission technique. A batch adsorption study was used to examine the performance efficiency of the modified clay. Optimization of adsorption conditions like temperature, particle size, concentration, agitation time and $\mathrm{pH}$ was performed. The clay after modification showed improved surface properties such as increased pore diameter and number. Freundlich, Langmuir and Temkin isotherm models were applied to explicate the adsorption processes, while Pseudo-First order, Pseudo-Second order and the Elovich kinetic models were used to predict possible mechanisms driving the adsorption processes. The adsorption processes driven by chemical mechanisms involved series of complex mechanisms that include ion exchange, direct bonding and surface complexation other than precipitation. The percentage removal of the metals by the modified clay soil reached the values of 98.53, 94.50, 73.82, and 80.40 for $\mathrm{Pb}, \mathrm{Cu}, \mathrm{Ni}$ and $\mathrm{Cr}$.
\end{abstract}

Keywords: kaolinite clay; heavy metals; clay modification; adsorption kinetics; adsorption isotherms

\section{- INTRODUCTION}

Environmental pollutants and their toxicity cause a major problem in the world. Water pollution is one of the biggest environmental issues causing serious problems to aquatic organisms and humans. Water bodies are majorly polluted by different industrial activities, including agrochemical production, dyeing, battery production, printing, mining, metallurgical engineering, electroplating, paint and pigment production, nuclear power operations, and electric appliances manufacturing, semiconductor production, cosmetics etc. [1-2]. The industries carrying out these operations generate various types of heavy metal pollutants in wastewater effluent. Heavy metals like chromium, nickel, cobalt, lead, arsenate and cadmium etc., in the aquatic environment, have been known to cause various health problems like chronic bronchitis, kidney problems, high blood pressure, reduced lung function, cancer of the lungs, intestinal cancer and fetal mortality [3-5].

To regulate the uncontrollable discharge of these heavy metals in wastewater, novel and recent water treatment technologies are being proposed globally. Several techniques like chemical precipitation, biological method, electrodialysis, ion exchange, electrochemical treatment and membrane filtration technologies, etc.,

Adekeye Damilola Kayode et al. 
have been used to remove hazardous pollutants [6-11]. The adsorption process is another suitable technique for heavy metal remediation in wastewater because of its significant advantages like low-cost, availability, profitability, ease of operation, high efficiency, and effectiveness over the other techniques [11-12].

Clays proposed as adsorption materials fulfill all requirements for low-cost chemical precursors for industrial applications [13-16]. Clays contain exchangeable cations and anions held to the surface [1718]. The uptake of heavy metals by clay minerals involves a series of complex adsorption mechanisms such as direct bonding between metal cations with the surface of clay minerals, surface complexation, and ion exchange etc. [19]. In many studies, surface modification is required to enhance the adsorption capacity of clays in order to increase metal uptake [20]. Surface modification enhances the surface area, pore diameter, and the number of present active sites on the surface [21]. Several researches have shown that modified clay is a promising low-cost technology for efficient and effective removal of metals like $\mathrm{Pb}, \mathrm{Ni}, \mathrm{Cr}$ and $\mathrm{Cu}$ contaminated water [21-24].

Researches have also shown that both raw and modified clays from Nigeria could find application for the de-metallization of wastewater containing heavy metals $[21,25]$. A previous study by Adekeye et al. [26] showed low removal efficiency by the clay for metals like chromium and nickel. The authors recommended the improvement of the surface properties of the clay for enhanced performance efficiency. The low removal efficiency of the clay for metals like chromium and nickel immensely necessitates and motivates the quest for modification. The present study is tailored towards the surface modification of the Ire-Ekiti clay for improved heavy metals adsorption properties. It is also aimed at elucidating the kinetics to show the kind of reaction between the adsorbates and adsorbent and the isotherm to explicate the processes to which the adsorbates were adsorbed. This would be the study that showed the kinetics and isotherm of the modified form of Ire-Ekiti clay for heavy metals adsorption.

\section{- EXPERIMENTAL SECTION}

\section{Materials}

Chemical and reagents used include copper(II) nitrate trihydrate $\left(\mathrm{Cu}\left(\mathrm{NO}_{3}\right)_{2} \cdot 3 \mathrm{H}_{2} \mathrm{O}\right)$, nickel(II) sulphate heptahydrate $\left(\mathrm{NiSO}_{4} .7 \mathrm{H}_{2} \mathrm{O}\right)$, potassium chromate $\mathrm{K}_{2} \mathrm{CrO}_{4}$, lead nitrate $\mathrm{Pb}\left(\mathrm{NO}_{3}\right)_{2}$, sodium dodecyl sulphate $\left(\mathrm{CH}_{3}\left(\mathrm{CH}_{2}\right)_{11} \mathrm{SO}_{4} \mathrm{Na}\right)$, sodium hydroxide solution $(\mathrm{NaOH})$, Hydrochloric acid solution $(\mathrm{HCl})$. All reagents used were of analytical grade; hence, no further purification was carried out before use.

\section{Instrumentation}

Instrumentations applied in adsorption experiment and for the characterization of clay samples include Scanning Electron Microscope coupled with Energy Dispersive X-ray Spectrophotometer (JEOL JSM-7600F), pH meter (Jenway pH meter 3520), rotary orbital shaker with incubator (Biosan environmental shaker-incubator ES-20/60), laboratory oven, Flame Atomic Absorption Spectrophotometer (Agilent AAS 55AA), X-ray fluorescence (XRF), Fourier Transformed Infrared spectrophotometer (SHIMADZU FTIR-8400S) and Particle Induced X-ray Emission (PIXE) technique.

\section{Study Area}

The study area and trial (sample collection) site 'Ire-Ekiti' is a town in Oye local government area of Ekiti State, Southwestern Nigeria, located between latitude $7^{\circ} 47^{\prime} \mathrm{N}$ to $7^{\circ} 53^{\prime} \mathrm{N}$ and longitude $5^{\circ} 18^{\prime} \mathrm{E}$ to $5^{\circ} 24^{\prime} \mathrm{E}$. The geological map is shown in Fig. 1. The town is known to have been the home of Ogun Onire, whom the Yoruba ethnic group of Nigeria recognizes as the "god of iron". Ire-Ekiti has naturally abundant clay deposits located within different settings of the town, which are mined both locally and industrially for different applications. The geological settings of Ekiti State are between latitude $7^{\circ} 20^{\prime} \mathrm{N}$ to $8^{\circ} 00^{\prime} \mathrm{N}$ and longitude $4^{\circ} 50^{\prime} \mathrm{E}$ to $5^{\circ} 50^{\prime} \mathrm{E}$. The trial site showing the effects of mining activities (a depression filled with water) is shown in Fig. 2. The town possesses the most abundant clay deposits in Ekiti state, and the quality of the clay for making various industrial products 


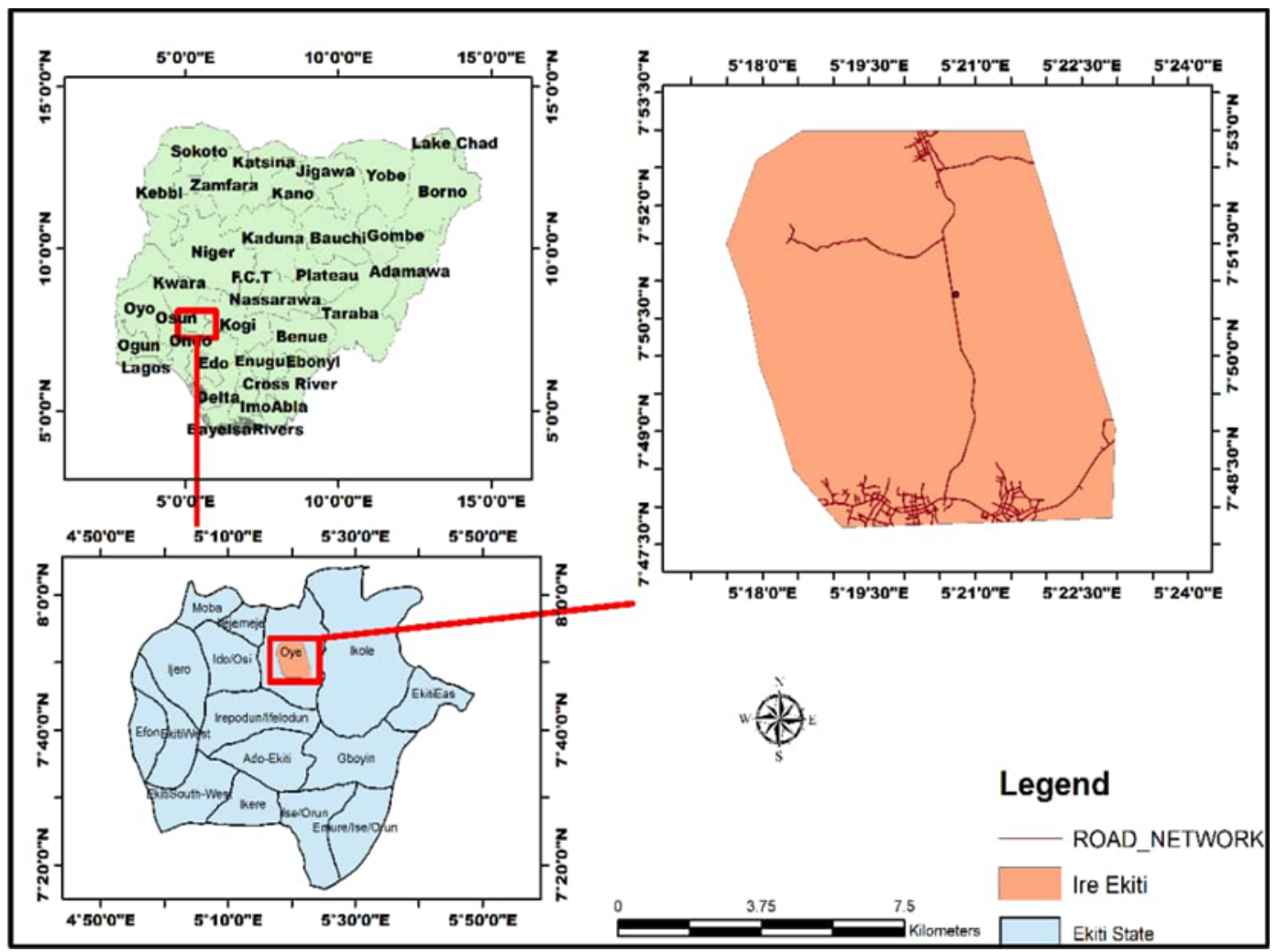

Fig 1. Geological map of Nigeria, Ekiti State, Oye local government area and Ire-Ekiti

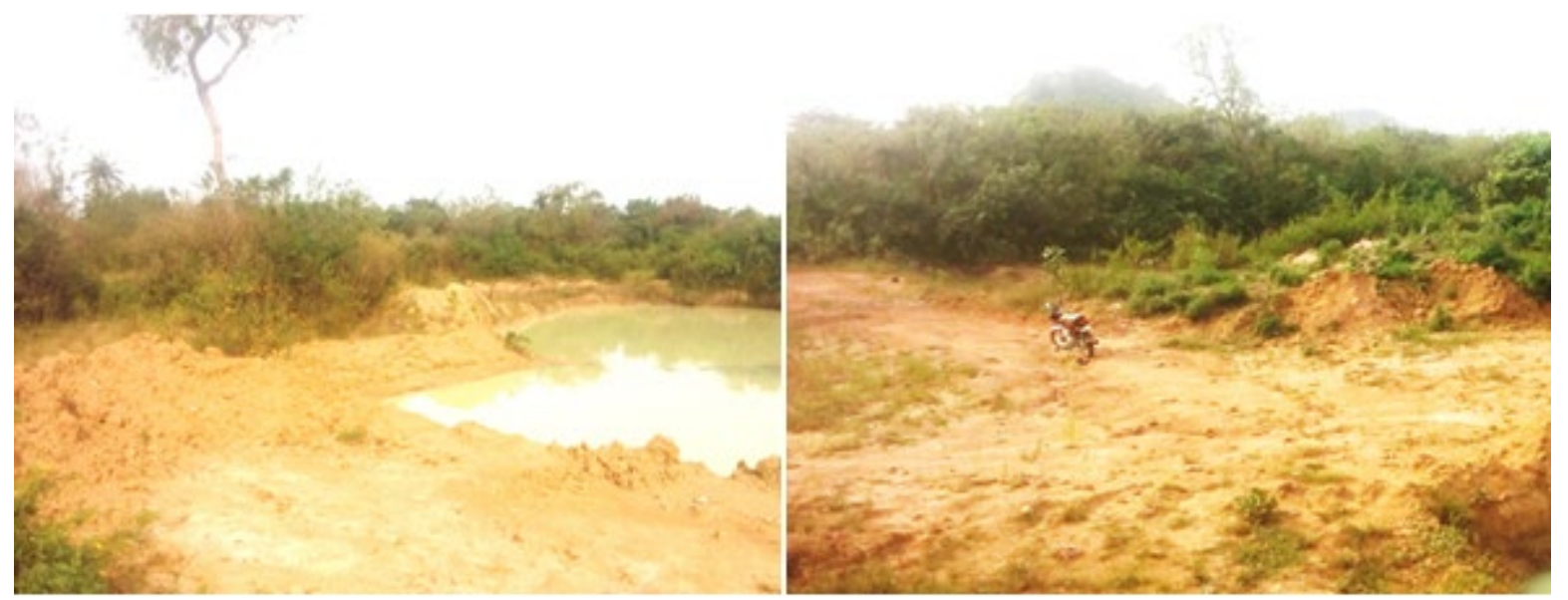

Fig 2. Figure of the trial site showing effects of mining activities

such as bricks, tiles and ceramics have drawn the attention of different miners and establishment of a clay processing industry in the town.

\section{Procedure}

\section{Collection and preparation of raw clay soil}

The clay soil was collected from Ire-Ekiti, Southwestern Nigeria. An adequate amount for use was crushed and dispersed in deionized water; then, floating debris from plants was removed by handpicking and also by decantation. The suspension was thoroughly stirred in order to allow none clay materials to be separated from the clay; the clay soil was recovered from the water by centrifuging the suspension at $3000 \mathrm{rpm}$. The recovered clay soil was dried at $110^{\circ} \mathrm{C}$ for about $12 \mathrm{~h}$ and cooled in a desiccator. After cooling, the dried clay 
soil was pulverized and sieved using sieves of different mesh sizes based on the experimental requirement. The sieved clay soils were stored in a black polyethylene bag prior to modification.

\section{Modification of clay soil sample}

An adequate amount of the raw clay sample to be used was modified with $100 \mathrm{~mL}$ of $0.01 \mathrm{M}$ SDS in $100 \mathrm{~mL}$ $0.01 \mathrm{M} \mathrm{NaCl}$ solution at $\mathrm{pH} 5$ by shaking for $90 \mathrm{~min}$ at $200 \mathrm{rpm}$ on a rotary orbital shaker. The $\mathrm{pH}$ of the solution was adjusted using $\mathrm{HCl}$ and $\mathrm{NaOH}$. After shaking, the mixture was centrifuged in order to collect the residue. The residue was collected and washed until the $\mathrm{pH}$ of leachate reached $\mathrm{pH}$ of 6.0 , then dried in an oven at $105{ }^{\circ} \mathrm{C}$ for $12 \mathrm{~h}$. The sample was crushed and sieved into the required particle sizes. The modified sample is called the surfactant (SDS) modified clay.

\section{Preparation of metal solution}

The stock solutions (1000 $\mathrm{mg} \mathrm{L}^{-1}$ ) of the adsorbates $(\mathrm{Ni}, \mathrm{Pb}, \mathrm{Cu}$, and $\mathrm{Cr}$ ) were prepared by dissolving known quantities of their metal salts (potassium chromate, lead nitrate, copper nitrate, and hydrated nickel sulfate) in deionized water and serially diluted to required concentration upon experimental requirement. The reagents used to prepare metal solutions were all extra pure analytical grades. The initial and equilibrium concentrations of metals were determined by Flame Atomic Absorption Spectrophotometer (Agilent AAS $55 \mathrm{AA})$.

\section{Characterization}

Different characterizations were carried out for both the raw and modified clay to ascertain surface modification and enhanced adsorption properties of the clay material. The chemical compositions of the clay samples were determined by X-ray Fluorescence (XRF). Fourier Transformed Infrared spectrometry (FTIR) was used for functional group elucidation and to confirm the surface modification. Scanning Electron Microscopy (SEM) was used to show the surface morphology of both the natural and modified clay soil samples. The elemental make-up of the clay samples was determined by Particle Induced X-ray Emission (PIXE), while the relative abundance $(\% \mathrm{w})$ of some important ionic compositions as well as the carbon content of the raw and modified clay materials, were determined by Energy Dispersive Xray Emission (EDX) technique.

\section{Batch adsorption experiments}

An adsorption experiment for the modified clay was carried out in batch by adding $50 \mathrm{~mL}$ of adsorbate solution $10 \mathrm{mg} \mathrm{L}^{-1}$ into conical flasks containing $0.50 \mathrm{~g}$ of the adsorbent [26]. Each adsorbent and adsorbate mixture was equilibrated at $\mathrm{pH} 5.0$ by shaking at $200 \mathrm{rpm}$ at a temperature of $298 \mathrm{~K}$, using a rotary orbital shaker until equilibrium. The $\mathrm{pH}$ of each solution was adjusted using drops of $\mathrm{HCl}$ and $\mathrm{NaOH}$ when necessary. After equilibration, the mixtures were centrifuged for $15 \mathrm{~min}$ at $3000 \mathrm{rpm}$. Thereafter, the supernatants were collected and analyzed for equilibrium concentrations of the $\mathrm{Cu}, \mathrm{Ni}, \mathrm{Pb}$, and $\mathrm{Cr}$ by an Atomic Absorption Spectrophotometer. The effect of $\mathrm{pH}$ on adsorption processes was studied at $\mathrm{pH} 3,4,5,7$, and 8 with an equilibration time of $90 \mathrm{~min}$. The effect of agitation time on the adsorption process was investigated at the time varied between 10 and 80 min at a $\mathrm{pH}$ value of 5 . Also, the adsorption of $\mathrm{Cu}, \mathrm{Ni}$, $\mathrm{Pb}$, and $\mathrm{Cr}$ on the modified clay material was optimized at different concentrations $(20,40,60,80$, and $100 \mathrm{ppm})$ with an equilibration time of $90 \mathrm{~min}$ at $\mathrm{pH} 5$.

\section{Data treatment}

The percentage metal removal was calculated according to Eq. (1)

$\%$ Metal removal $=\frac{\mathrm{C}_{0}-\mathrm{C}_{\mathrm{e}}}{\mathrm{C}_{0}} \times 100 \%$

where $\mathrm{C}_{0}\left(\mathrm{mg} \mathrm{L}^{-1}\right)$ and $\mathrm{C}_{\mathrm{e}}\left(\mathrm{mg} \mathrm{L}^{-1}\right)$ are the initial and equilibrium adsorbate concentration, respectively.

\section{- RESULTS AND DISCUSSION}

\section{Surface Morphology}

A scanning electron microscope image showing the morphology of the raw Ire-Ekiti clay soil is presented in Fig. 3(a). The image of the natural clay presents a very rough surface arising from a dense stacking and piling of particles upon one another and resulting in small-size inter-aggregate pores $(10 \mu \mathrm{m})$. In this structure, the piling of the particles is in a consistent order, forming a tangled network with a highly dense arrangement of the 

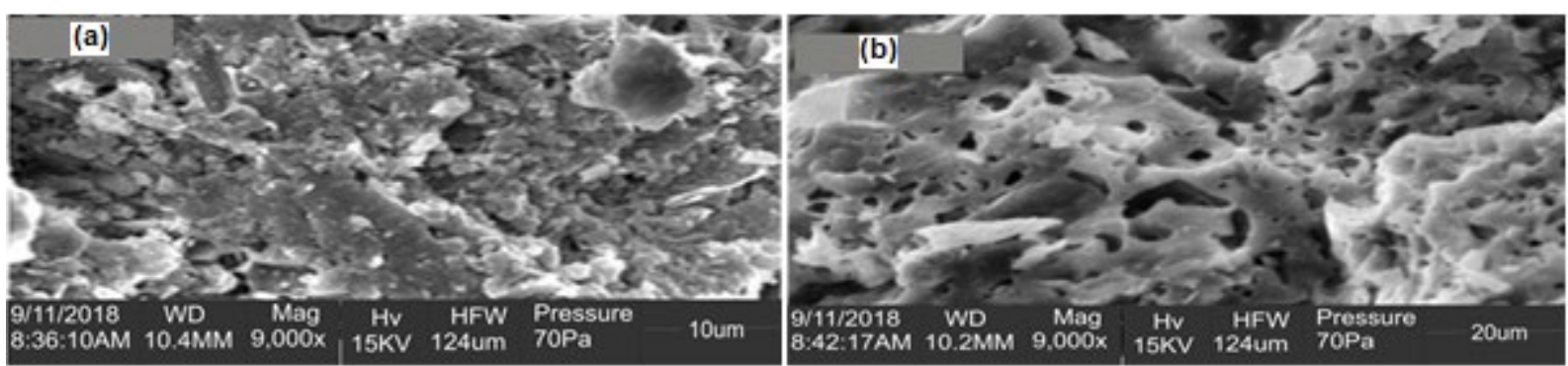

Fig 3. (a) Scanning electron microscope image of the raw clay; (b) Scanning electron microscope image of the modified clay

particles resulting in a reduced number of pores. The small pore size may hinder the permeability of adsorbates and result in low diffusion and reduced adsorption [26]. The SEM image of the modified clay is shown in Fig. 3(b). Modification of the raw clay changed its structure and surface morphology. The modified clay showed a honeycomb-like structure and surface morphology with improved surface adsorptive properties like increased pore number and size. The most notable improved properties are the pore diameter $(20 \mu \mathrm{m})$ and number. The pore diameter increased from 10 to $20 \mu \mathrm{m}$. Also, the pores are more numerous compared to those of the raw clay, as shown in Fig. 3(a) and 3(b). These properties make the modified clay more porous. The numerous pores and improved pore diameter have the potency to enhance permeation of the adsorbates during adsorption experiments. The highly porous structure of the SDS modified clay could improve intraparticle diffusion and permeation, resulting in higher adsorption of the adsorbate by enhancing the inner-sphere complexation reaction between the adsorbates and adsorbent.

\section{FTIR Adsorption Spectroscopy Bands}

The results of the FTIR analysis of the modified and raw clay are shown in Fig. 4(a) and 4(b), respectively.

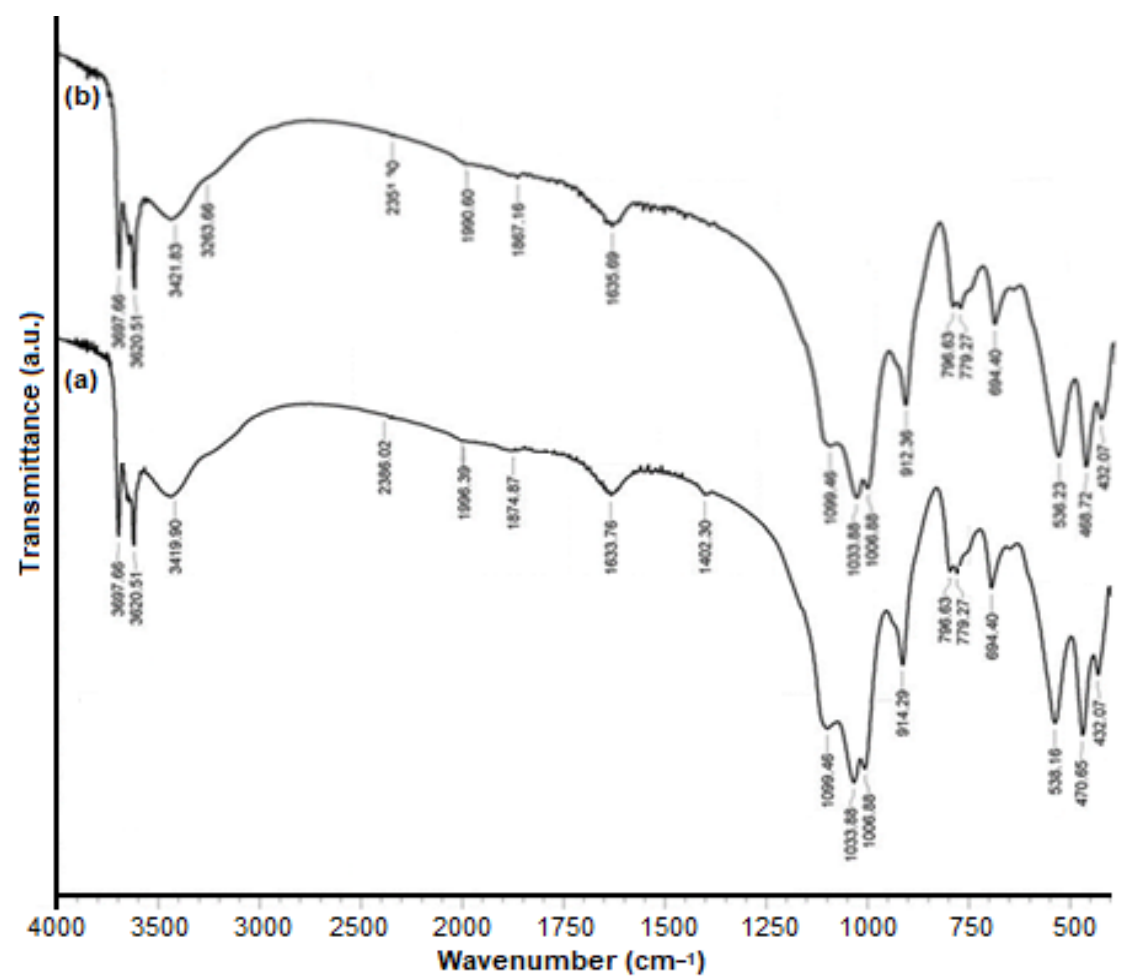

Fig 4. Fourier transform infrared spectra of (a) the SDS modified clay soil, and (b) the raw clay soil 
The FTIR results showed absorption bands at 3620, 3421, $3263,3697,3620$, and $3419 \mathrm{~cm}^{-1}$, which are due to the hydroxyl group of the inner surface of the clays. The bands at 1099 and $1006 \mathrm{~cm}^{-1}$ correspond to the $\mathrm{Si}-\mathrm{O}-\mathrm{Si}$ group present in the clays; the band at $694 \mathrm{~cm}^{-1}$ is due to the bending mode of the same group. The absorption bands at 1633 and $1402 \mathrm{~cm}^{-1}$ are due to the presence of $\mathrm{C}=\mathrm{O}$ and $\mathrm{C}=\mathrm{C}$ of the organic components of the clay soils. The bands at 536 and $538 \mathrm{~cm}^{-1}$ showed the presence of the $\mathrm{Si}-\mathrm{O}-\mathrm{Al}$ group in the raw and modified clay. The presence of metallic oxide in the clay soil is indicated by the intensity bands at 468 and $432 \mathrm{~cm}^{-1}$ [27-28]. The appearance of a new intensity band at $1402 \mathrm{~cm}^{-1}$ assigned to the $\mathrm{C}=\mathrm{C}$ in the modified clay soil, which is not present in the raw clay soil, is due to surface modification of the soil. The presence of the band $3263 \mathrm{~cm}^{-1}$ in the raw clay and its disappearance in the modified clay soil is a result of surface modification of the soil. Shifts in the adsorption bands from $2351,1990,1867,912$, and $468 \mathrm{~cm}^{-1}$ of the raw clay to higher intensity bands of 2386, 1996 1874, 914, and $470 \mathrm{~cm}^{-1}$ in the modified clay also confirm the surface modification. The changes in the FTIR results of the raw clay upon modification showed that modification with SDS might have possibly improved the negative charges of the clay surfaces and created more active sites for metal binding. The $\mathrm{Si}-\mathrm{O}-\mathrm{Al}$ and $\mathrm{Si}-\mathrm{O}-\mathrm{Si}$ structures of the soil were not affected by the modification.

\section{Chemical Composition}

The chemical composition presented in Table 1 showed that silica and alumina are the major constituents of the raw and modified clay with a percentage composition of 55.80 and $24.28 ; 56.31$ and 27.07, respectively. The XRF results also showed that the metals are present in their oxide form rather than hydroxide. Silica $\left(\mathrm{SiO}_{2}\right)$ and alumina $\left(\mathrm{Al}_{2} \mathrm{O}_{3}\right)$, being the major constituents of the clay soil, suggest that the clay soil is an alumino-silicate (kaolinite). The percentage of metal oxide compositions of the raw clay increased upon modification except for $\mathrm{MnO}$. This showed that modification could also affect the chemical composition of clay soil. The results of this study are consistent and agreed with the result obtained from a study reported by Akinola et al. [29] and Awokunmi and
Table 1. Chemical composition of SDS modified IreEkiti clay soil

\begin{tabular}{lcc}
\hline Oxide & $\begin{array}{c}\text { Chemical composition } \\
\text { of the raw clay (\%) }\end{array}$ & $\begin{array}{c}\text { Chemical composition of } \\
\text { the modified clay (\%) }\end{array}$ \\
\cline { 2 - 3 } $\mathrm{SiO}_{2}$ & 55.80 & 56.31 \\
$\mathrm{Al}_{2} \mathrm{O}_{3}$ & 24.28 & 27.07 \\
$\mathrm{Fe}_{2} \mathrm{O}_{3}$ & 4.16 & 4.89 \\
$\mathrm{Na}_{2} \mathrm{O}$ & 2.91 & 2.92 \\
$\mathrm{~K}_{2} \mathrm{O}$ & 0.32 & 0.32 \\
$\mathrm{MgO}$ & 1.54 & 1.70 \\
$\mathrm{CaO}$ & 0.27 & 0.50 \\
$\mathrm{TiO}_{2}$ & 0.2 & 0.26 \\
$\mathrm{ZrO}$ & 0.06 & 0.07 \\
$\mathrm{MnO}_{\mathrm{LOI}}$ & 0.03 & 0.03 \\
$\mathrm{Total}$ & 10.30 & 5.65 \\
\hline
\end{tabular}

Asaolu [30] on the modification of clay soil from Ekiti State for fluoride adsorption in an aqueous medium.

\section{Elemental Composition}

The result from the Proton Induced X-ray Emission technique (Table 2) showed that silicon ( $\mathrm{Si}$, $558138 \mathrm{ppm}$ ) and Aluminum (Al, $242444 \mathrm{ppm}$ ) are the major elemental composition with the highest concentration in the raw clay soil matrix. $\mathrm{Al}$ (271498 ppm) and $\mathrm{Si}(564580 \mathrm{ppm})$ are also the major elemental composition with the highest concentration in the modified clay soil matrix. These results corroborate the results of the XRF, which showed that silica and alumina are the major chemical composition of both the raw and SDS modified clay soils. The elemental composition of the raw and modified clays also showed that the clay soil samples contained a high concentration of some important exchangeable cations. The exchangeable cations for the modified clay include $\mathrm{Na}^{+}(29473 \mathrm{ppm})$, $\mathrm{Mg}^{2+}$ (17018 ppm), $\mathrm{Ca}^{2+}$ (5056 ppm) and $\mathrm{Fe}^{2+}$ (49888 ppm). The presence of these exchangeable cations in the soil could bring about a cation exchange mechanism for removing the adsorbates from their respective solution. The concentration of each exchangeable cation of the modified clay is higher than those of the raw clay $\left(\mathrm{Na}^{+}\right.$ (28810 ppm), $\mathrm{Mg}^{2+}$ (15311 ppm), $\mathrm{Ca}^{2+}$ (2723 ppm), and $\mathrm{Fe}^{2+}(41320 \mathrm{ppm})$. 
Table 2. Elemental composition and concentration of SDS modified Ire-Ekiti clay soil

\begin{tabular}{|c|c|c|c|}
\hline $\mathrm{Z}$ & Symbol & $\begin{array}{c}\text { Elemental concentration } \\
\text { of the raw clay (ppm) }\end{array}$ & $\begin{array}{l}\text { Elemental concentration } \\
\text { of the modified clay (ppm) }\end{array}$ \\
\hline 11 & $\mathrm{Na}$ & 28810 & 29473 \\
\hline 12 & $\mathrm{Mg}$ & 15311 & 17018 \\
\hline 13 & $\mathrm{Al}$ & 242444 & 271498 \\
\hline 14 & $\mathrm{Si}$ & 558138 & 564580 \\
\hline 15 & $\mathrm{P}$ & 329 & 400 \\
\hline 17 & $\mathrm{Cl}$ & 281 & 386 \\
\hline 19 & $\mathrm{Kf}$ & 3101 & 3154 \\
\hline 20 & $\mathrm{Ca}$ & 2723 & 5056 \\
\hline 22 & $\mathrm{Ti}$ & 2097 & 2687 \\
\hline 24 & $\mathrm{Cr}$ & 261 & 309 \\
\hline 25 & $\mathrm{Mn}$ & 312 & 318 \\
\hline 26 & $\mathrm{Fe}$ & 41320 & 49888 \\
\hline 29 & $\mathrm{Cu}$ & 381 & 452 \\
\hline 30 & $\mathrm{Zn}$ & 138 & 180 \\
\hline 38 & $\mathrm{Sr}$ & 35.8 & 187 \\
\hline 40 & $\mathrm{Zr}$ & 562 & 690 \\
\hline 46 & $\mathrm{Pd}$ & 20.5 & 35.7 \\
\hline 47 & Ag & 217 & 273 \\
\hline 48 & $\mathrm{Cd}$ & 91.6 & 107 \\
\hline 50 & $\mathrm{Sn}$ & 218 & 283 \\
\hline 82 & $\mathrm{~Pb}$ & 13.8 & 13.2 \\
\hline 83 & $\mathrm{Bi}$ & - & 45.9 \\
\hline
\end{tabular}

Where $\mathrm{Z}$ is the atomic number

The metals were assumed to have undergone chemical multiplication or amplification reactions during the modification process, which resulted in their respective concentration increase. This improvement in the exchangeable cation concentrations could consequently increase the cation exchange capacity of the soil and enhance the adsorption of the adsorbates through an improved cation exchange mechanism. Bismuth (Bi) was present in the raw clay soil but absent in the modified clay soil. The absence of bismuth in the modified clay is probably due to the effect of modification of the raw clay soil.

\section{Carbon and Ionic Composition of the Raw and Modified Soil Sample}

Results of the EDX analysis of both the raw and modified clay soil samples (Fig. 5(a) and 5(b)) showed that aluminum, silicon, and oxygen are the most abundant ionic compositions of the soil matrixes and possessing the highest percentage by weight $(\% \mathrm{w})$. The value of $\mathrm{Al}$, Si and $\mathrm{O}$ of the raw clay soil are 10.10, 49.30, and $13.0 \% \mathrm{w}$, while that of the modified clay soil are $13.00,50.00$, and $20.70 \% \mathrm{w}$, respectively. The absence of hydrogen and the presence of oxygen is an indication that the elements could be present in the form of oxides rather than hydroxide. This supports the results of the FTIR, PIXE, and XRF analysis obtained for the samples. In agreement with other techniques that have been applied for probing the properties and compositional characteristics of both the raw and modified clay samples in the present study, the EDX results of the raw clay sample also showed the presence of some important exchangeable cations such as $\mathrm{K}(3.17 \% \mathrm{w}), \mathrm{Ca}(5.47 \% \mathrm{w})$ 


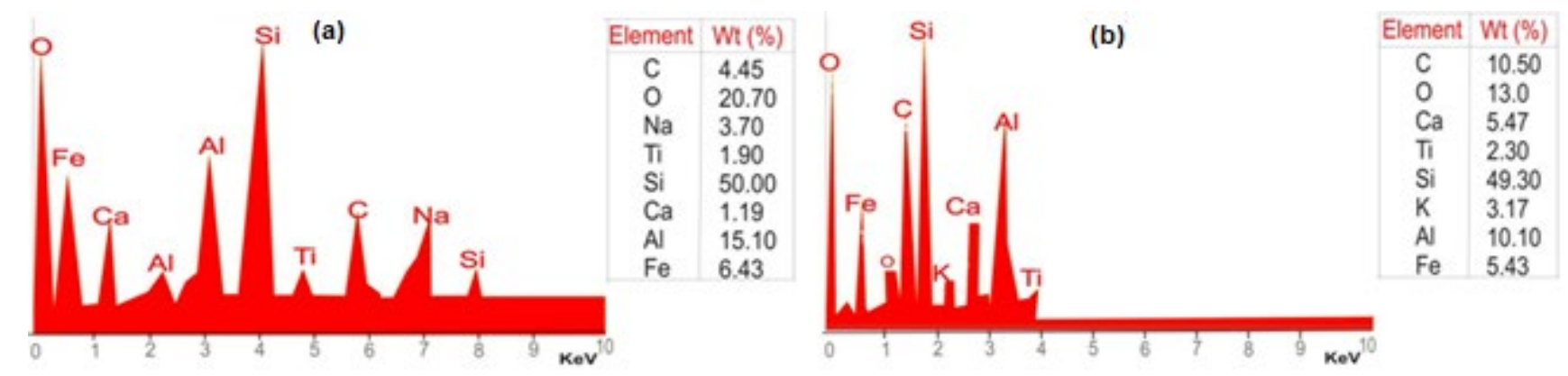

Fig 5. EDX analytical results of (a) the raw clay soil, (b) the modified clay soil

and $\mathrm{Fe}(5.43 \% \mathrm{w})$ while the modified clay showed the presence of $\mathrm{Na}(3.70 \% \mathrm{w}), \mathrm{Ca}(1.19 \% \mathrm{w})$ and $\mathrm{Fe}(6.43 \% \mathrm{w})$. It was observed that modification has a significant influence on the ionic composition of the clay soil. For instance, $\mathrm{K}$ was present in the raw clay and absent in the modified clay. The absence of $\mathrm{K}$ in the modified clay may be due to the leaching of $\mathrm{K}$ from the clay during the modification process. The percentage composition of the elemental composition of the raw clay is different from that of the modified clay, as shown in Fig. 5(a) and 5(b). The carbon content of the raw and modified has the value of $10.50 \%$ and $4.45 \%$, respectively. The relative abundance (percentage by weight) of $\mathrm{Si}$ and $\mathrm{Al}$ compared to other elements showed that the clay soil is typically kaolin confirming the results of the PIXE and XRF analysis.

\section{Effect of pH}

The $\mathrm{pH}$ of a solution determines the degree of ionization and speciation of metal ions and also affects the surface charge of an adsorbent in the process of metal uptake [31]. From the results in Fig. 6, it is shown that the optimum adsorption of $\mathrm{Ni}, \mathrm{Pb}$, and $\mathrm{Cu}$ was obtained at $\mathrm{pH} 4.0$, while that of $\mathrm{Cr}$ was obtained at $\mathrm{pH}$ 5.0. This showed that optimum adsorption could be achieved at an acidic medium (usually, at $\mathrm{pH}$ greater than 2.0 ) without chemical precipitation of the hydroxide form of the metal adsorbates. This is in agreement with previously reported works by Erdemoglu et al. [32] and Chaari et al. [33]. The results obtained for the adsorption trend with increased $\mathrm{pH}$ showed that the adsorption process involved series of complex mechanisms, which include ion exchange, direct bonding, and surface complexation other than precipitation.

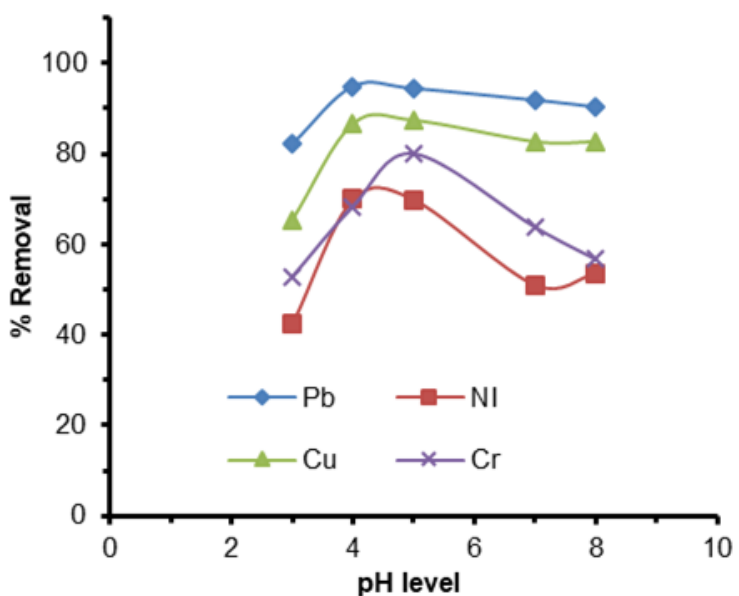

Fig 6. Adsorption trend with increase $\mathrm{pH}$ of the metals' solution

\section{Effect of Agitation Time}

The effect of agitation time on the adsorption potential of the modified clay material was investigated to show the suitability of the clay material for industrial applications. A good adsorbent suitable for industrial applications usually possesses a high adsorption capacity as well as a fast rate of removal. Equilibration time for adsorption of $\mathrm{Cu}$ and $\mathrm{Pb}$ was fast and achieved within 30 and 40 min respectively; then tended to be constant for $80 \mathrm{~min}$. The fast adsorption rate of the adsorption process is probably due to the increased concentration gradient between the adsorbate in the solution and adsorbate in the adsorbent. This difference in concentration determined the number of vacant and available sites for metal binding and enhanced the increased uptake of the metals at the initial stages of the adsorption processes. This also implies that the nature of an adsorbent and its active sites determine the rate at 
which equilibrium is attained, as suggested by Dal Bosco et al. [34]. Similar results were observed in a study conducted by Jaiswal et al. [35]. Equilibration of $\mathrm{Ni}$ (50 $\mathrm{min})$ and $\mathrm{Cr}(60 \mathrm{~min})$ was achieved at a slower rate, as shown in Fig. 7. The slower rate of adsorption of $\mathrm{Ni}$ and $\mathrm{Cr}$ implies that the nature of adsorbates also plays a significant role in the rate at which equilibrium is attained or the rate of uptake. The progressive increase in adsorption and, consequently, the attainment of equilibrium adsorption may be due to limited mass transfer of the adsorbate particles from the adsorbate solution to the external surface of the clay material, initially and subsequently by slower internal mass transfer within the clay particles [36].

\section{Effect of Adsorbate Concentration}

The equilibrium adsorption trend for $\mathrm{Ni}, \mathrm{Pb}, \mathrm{Cr}$ and $\mathrm{Cu}$ by the modified clay material is shown in Fig. 8 . Adsorptions of $\mathrm{Ni}, \mathrm{Pb}$, and $\mathrm{Cu}$ tend to increase as the concentration of the metals in the solution increased. It was observed that increasing the concentration of the metals in the solution resulted in higher uptake of the metal until equilibrium was achieved. This trend was attributed to the fact that when the transport of metals between the adsorbent's internal pores and external surface films tends to be equal, the transboundary movement of metals will not be significantly permissible; however, increasing concentration will re-initiate the movement, and for this reason, the adsorption process

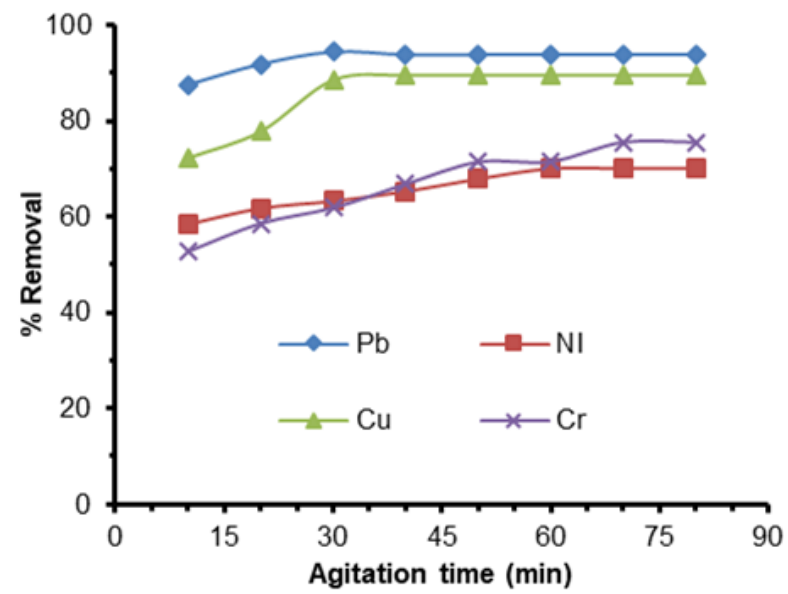

Fig 7. Adsorption trend with increase contact time for the metals will be dependent [37]. Similar findings have been reported in the literature for similar and other pollutants' adsorption [38-39]. The effect of initial concentration on $\mathrm{Cr}$ adsorption by the modified clay showed that the percentage of $\mathrm{Cr}$ adsorbed decreased with increasing concentration. This decrease was a result of saturation of the active sites of the adsorbents at higher metal concentrations leading to less removal of chromium ions from the solution. This implies that at low concentrations, more chromium ions would be removed by the abundant active sites on the adsorbents. This result is in accordance with the findings by Akpomie et al. [21] in their study of the enhanced sorption of trivalent chromium unto novel cassava peel modified kaolinite clay.

\section{Effect of Temperature}

Temperature is one of the most important parameters of adsorption, and its effect on the metals uptake was investigated. The result of the study is shown in Fig. 9. The result showed that the adsorption process for all the metals increases with the increased temperature of the solution and suggesting endothermicity of the adsorption process. The adsorption trend is due to the ability of the metals in solution (lead, copper, chromium, and nickel) to overcome resistance to mass transfer with an increase in kinetic energy as they undergo interactions with active sites of the clay material. Increased temperature has been reported to favour the uptake of

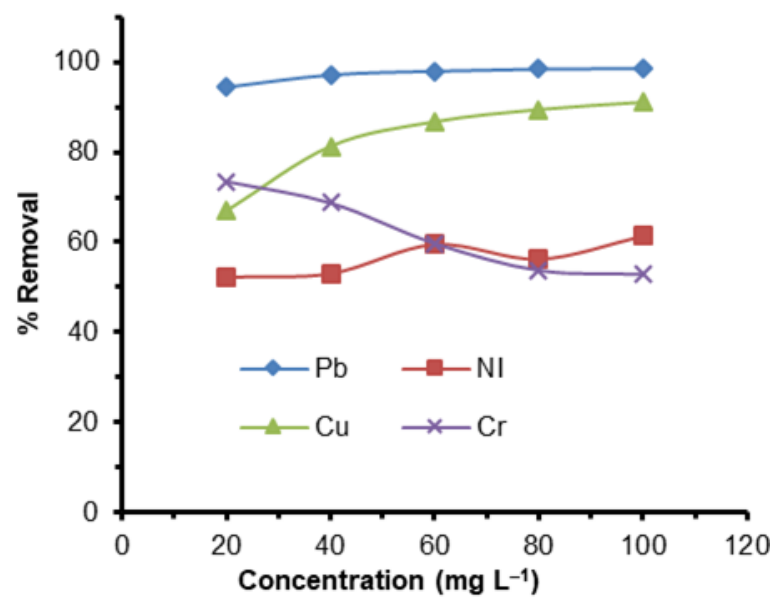

Fig 8. Adsorption trend with increase concentration for the metals 


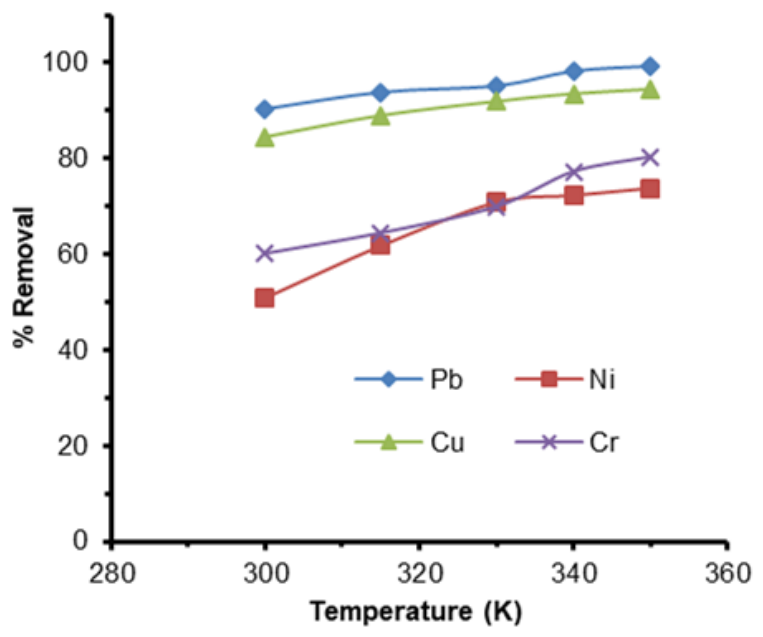

Fig 9. Adsorption trend with increase temperature for the metals

dyes and pigments Rattanaphani et al. [40] while the adsorption of metals was equally favored by increased temperature, as reported by Zouraibi et al. [41].

\section{Effect of Adsorbate Particle Size}

Adsorption processes have been known to be particle dependent. Results from this study showed that adsorption of $\mathrm{Ni}, \mathrm{Pb}, \mathrm{Cu}$, and $\mathrm{Cr}$ by the modified clay material increased with decreased particle size (Fig. 10). This is due to the fact that a decrease in particle size of an adsorbent would yield larger surface areas and make available more active sites for metal binding [42].

\section{Langmuir Adsorption Isotherm}

The linearized Langmuir equation Kinniburgh [43] was used to show the surface binding properties of the metals on the modified clay soils.

$\frac{1}{\mathrm{q}}=\frac{1}{\mathrm{Q}_{\mathrm{o}}}+\frac{1}{\mathrm{Q}_{\mathrm{o}} \mathrm{K}_{\mathrm{L}} \mathrm{C}_{\mathrm{e}}}$

where $\mathrm{q}_{\mathrm{e}}\left(\mathrm{mg} \mathrm{g}^{-1}\right)$ represents the amount of ion adsorbed, $\mathrm{C}_{\mathrm{e}}\left(\mathrm{mg} \mathrm{L}^{-1}\right)$ is the equilibrium concentration, $\mathrm{Q}_{\mathrm{o}}\left(\mathrm{q}_{\max }\right)$ maximum is monolayer coverage capacity $\left(\mathrm{mg} \mathrm{g}^{-1}\right)$, and $\mathrm{K}_{\mathrm{L}}$ $\left(\mathrm{L} \mathrm{mg}^{-1}\right)$ represents the Langmuir adsorption equilibrium constant. The values of $\mathrm{K}_{\mathrm{L}}$ and $\mathrm{q}_{\max }$ were determined from the slope and intercept of the Langmuir plot of $1 / q_{e}$ against $1 / C_{e}$. An essential feature of the Langmuir isotherm was also expressed in terms of equilibrium parameter $\mathrm{R}_{\mathrm{L}}$, known as the separation factor, which is a dimensionless constant and represented by Eq. (3).

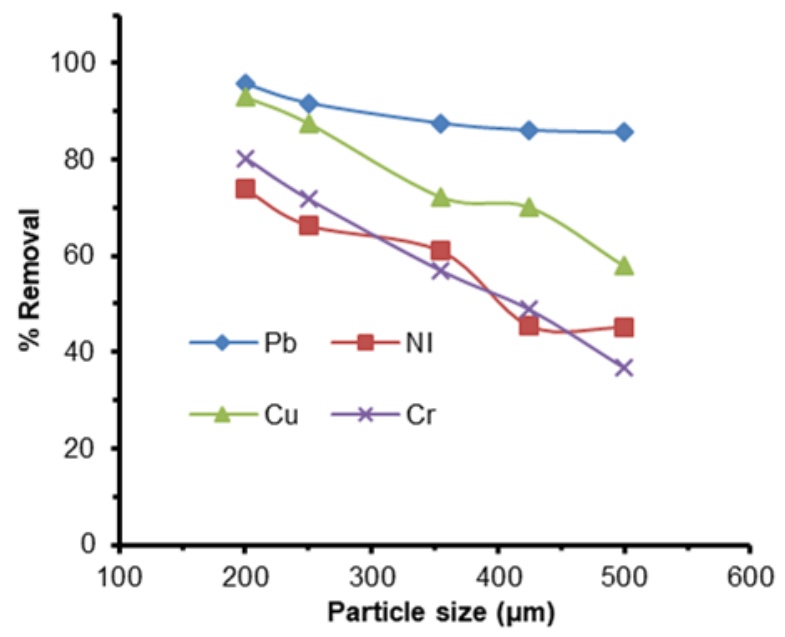

Fig 10. Adsorption trend with increase particle size for the metals

$\mathrm{R}_{\mathrm{L}}=\frac{1}{1+\left(1+\mathrm{K}_{\mathrm{L}} \mathrm{C}_{\mathrm{o}}\right)}$

where $\mathrm{C}_{0}$ represents the initial concentration and $\mathrm{K}_{\mathrm{L}}$ is a constant related to the energy of adsorption. If the value of $\mathrm{K}_{\mathrm{L}}$ is less than $(<) 0$, it implies that the adsorption process does not correlate to Langmuir isotherm. The adsorption nature is unfavorable if $\mathrm{R}_{\mathrm{L}}$ is greater than 1 , it is linear if $R_{L}=1$, irreversible if $R_{L}=0$, and favorable if $0<\mathrm{R}_{\mathrm{L}}<1$. A negative $\mathrm{R}_{\mathrm{L}}$ value indicates that the adsorption process does not fit the Langmuir isotherm, and hence, it cannot be explained by the Langmuir isotherm.

The data presented in Table 3 shows that the $\mathrm{K}_{\mathrm{L}}$ and $\mathrm{R}_{\mathrm{L}}$ values for adsorption of $\mathrm{Pb}, \mathrm{Ni}$, and $\mathrm{Cu}$ on the modified clay are $<0$. This showed that the adsorption processes do not fit the Langmuir isotherm. On the other hand, the $\mathrm{K}_{\mathrm{L}}$ value for $\mathrm{Cr}$ on the modified clays is 26.88 $\mathrm{L} \mathrm{mg}^{-1}$. Also, an $\mathrm{R}_{\mathrm{L}}$ value in the range of $3.7 \times 10^{-5}-1.9 \times$ $10^{-4}$ was also obtained for $\mathrm{Cr}$ adsorption on the modified clay material. The $\mathrm{R}_{\mathrm{L}}$ value for chromium adsorption on and modified clay is greater than 0 but less than 1 , which implies a favored Langmuir isotherm; the positive $\mathrm{K}_{\mathrm{L}}$ values indicate that the adsorption processes correlate to the Langmuir isotherm. The $\mathrm{R}^{2}$ values for the $\mathrm{Cr}, \mathrm{Pb}, \mathrm{Cu}$, and $\mathrm{Ni}$ adsorption onto the modified clay are 0.9538 , $0.5119,0.9215$, and 0.9864 , respectively. The positive $\mathrm{K}_{\mathrm{L}}$ values of $\mathrm{Cr}$ and other data obtained from all isotherms showed that chromium adsorption on the modified clay is in best compliance and correlates to the Langmuir 
Table 3. Langmuir isotherm parameters for the modified clay material

\begin{tabular}{cllll}
\hline Parameters & \multicolumn{1}{c}{$\mathrm{Ni}$} & \multicolumn{1}{c}{$\mathrm{Pb}$} & $\mathrm{Cu}$ & $\mathrm{Cr}$ \\
\hline $\mathrm{R}^{2}$ & 0.9864 & 0.5119 & 0.9215 & 0.9538 \\
$\mathrm{q}_{\max }$ & 0.097 & 0.715 & 0.058 & 0.3378 \\
$\mathrm{~K}_{\mathrm{L}}$ & -87.34 & -1.517 & -9.007 & 26.882 \\
$\mathrm{R}_{\mathrm{L}}$ & $-\left(1.15 \times 10^{-6}-3 \times 10^{-4}\right)$ & $-\left(6.64 \times 10^{-5}-3.41 \times 10^{-4}\right)$ & $-\left(5.6 \times 10^{-3}-1 \times 10^{-3}\right)$ & $\left(3.7 \times 10^{-5}-1.9 \times 10^{-4}\right)$ \\
\hline
\end{tabular}

isotherm as the negative $\mathrm{K}_{\mathrm{L}}$ values (Table 3) of other metals showed their unfitness to the isotherm. These results imply monolayer adsorption of Cr on the clays' flat surfaces. The correlation was not only determined by the (coefficient of determination) linear regression coefficient parameter but also the $K_{L}$ value as the $R^{2}$ value is not enough to describe the fitness and correlation of an adsorption process to Langmuir isotherm.

\section{Freundlich Isotherm}

Freundlich isotherm was used to predict a possible multi-layer adsorption of the metals on the clays' rough surfaces. The Freundlich isotherm was elucidated using Eq. (4) and (5) [44].

$\mathrm{q}_{\mathrm{e}}=\mathrm{K}_{\mathrm{F}} \mathrm{C}_{\mathrm{e}}^{1 / \mathrm{n}}$

where $\mathrm{n}$ is adsorption intensity, $\mathrm{K}_{\mathrm{F}}$ is Freundlich isotherm constant $\left(\mathrm{mg} \mathrm{g}^{-1}\right)$, and $\mathrm{C}_{e}$ represents the equilibrium concentration of adsorbate $\left(\mathrm{mg} \mathrm{L}^{-1}\right)$. Hence,

$\log \mathrm{q}_{\mathrm{e}}=\log \mathrm{K}_{\mathrm{F}}+\frac{1}{\mathrm{n}} \log \mathrm{C}_{\mathrm{e}}$

where $K_{F}$ and $1 / n$ are empirical constants, indicating the adsorption capacity and the strength of adsorption in an adsorption process, respectively. Parameters for the constants were obtained by plotting $\log \mathrm{q}_{\mathrm{e}}$ versus $\log \mathrm{C}_{\mathrm{e}}$ [45]. If the obtained value for $1 / n$ is below 1 , it indicates normal adsorption. On the other hand, if the value of $1 / n$ is above 1, it implies cooperative adsorption [46].

Linear regression parameter is used to determine the fitness of kinetics and isotherm models [47]. From the data presented in Table 4 , the values of $1 / n$ are greater than 1 for $\mathrm{Cr}, \mathrm{Pb}$ and $\mathrm{Cu}$ adsorption by the modified clay material. This indicates that the adsorption processes are cooperative while the adsorption of $\mathrm{Ni}$ is more favored. The $\mathrm{R}^{2}$ values of 0.9895 and 0.9806 were obtained for the $\mathrm{Cu}$ and $\mathrm{Ni}$, respectively, from the Freundlich adsorption isotherm plot. The adsorption processes of the $\mathrm{Cu}$ and $\mathrm{Ni}$ on the modified clay fits best to the Freundlich isotherm than other tested adsorption isotherms. This implies that the adsorption process describes a heterogeneous system characterized by multi-layer adsorption on the rough surfaces of the clay material.

\section{The Temkin Isotherm}

The Temkin isotherm, which contains factors (Table 5) that explicitly takes into account 'adsorbentadsorbate interactions', was used to show that heat of adsorption of $\mathrm{Pb}$ molecules in layers would decrease linearly rather than logarithmic with coverage by ignoring the extremely low and large value of the concentrations. The isotherm was computed using Eq. (6) and (7) [48].

$$
\begin{aligned}
& \mathrm{q}_{\mathrm{e}}=\frac{\mathrm{RT}}{\mathrm{b}} \ln \left(\mathrm{A}_{\mathrm{T}} \mathrm{C}_{\mathrm{e}}\right) \\
& \mathrm{q}_{\mathrm{e}}=\frac{\mathrm{RT}}{\mathrm{b}} \ln \mathrm{A}_{\mathrm{T}}+\left(\frac{\mathrm{RT}}{\mathrm{b}}\right) \ln \mathrm{C}_{\mathrm{e}} \\
& \mathrm{B}=\frac{\mathrm{RT}}{\mathrm{b}_{\mathrm{T}}} \\
& \mathrm{q}_{\mathrm{e}}=\mathrm{B} \ln \mathrm{A}_{\mathrm{T}}+\mathrm{B} \ln \mathrm{C}_{\mathrm{e}}
\end{aligned}
$$

Table 4. Freundlich isotherm parameters for the modified clay material

\begin{tabular}{cllll}
\hline Parameters & \multicolumn{1}{c}{$\mathrm{Cu}$} & \multicolumn{1}{c}{$\mathrm{Ni}$} & $\mathrm{Cr}$ & $\mathrm{Pb}$ \\
\hline $\mathrm{R}^{2}$ & 0.9895 & 0.9806 & 0.0452 & 0.8956 \\
$\mathrm{~K}_{\mathrm{f}}$ & $4.19 \times 10^{-6}$ & 9.56 & 1.778 & 7.863 \\
$\mathrm{n}$ & 0.149 & 1.25 & 0.131 & 0.097 \\
$1 / \mathrm{n}$ & 6.729 & 0.799 & 7.663 & 10.29 \\
\hline
\end{tabular}


where $A_{T}$ is Temkin isotherm equilibrium binding constant $\left(\mathrm{L} \mathrm{g}^{-1}\right), \mathrm{b}_{\mathrm{T}}$ is Temkin isotherm constant, $\mathrm{R}$ is the universal gas constant $\left(8.314 \mathrm{~J} \mathrm{~mol}^{-1} \mathrm{~K}^{-1}\right), \mathrm{T}$ is Temperature at $298 \mathrm{~K}$, and $\mathrm{B}$ is Constant related to the heat of adsorption $(\mathrm{J} / \mathrm{mol}) . \mathrm{A}_{\mathrm{T}}$ and $\mathrm{B}$ were determined by plotting the quantity adsorbed $\mathrm{q}_{e}$ against $\ln \mathrm{C}_{e}$ and the constants were determined from the slope and intercept [48].

The following values shown in Table 5 were estimated for the adsorption of $\mathrm{Pb}$ on the modified clay: $\mathrm{A}_{\mathrm{T}}=0.943 \mathrm{~L} \mathrm{~g}^{-1}, \mathrm{~b}_{\mathrm{T}}=47.87$ and $\mathrm{B}=52.11 \mathrm{~J} \mathrm{~mol}^{-1}$. The parameters obtained from all the tested isotherms showed that the Temkin plot is the best fitting isotherm for the adsorption of $\mathrm{Pb}$ onto the modified clay with an $\mathrm{R}^{2}$ value of 0.9655. This implies monolayer adsorption of the $\mathrm{Pb}$ particles in layers on the modified clay, whereas the heat of adsorption decreased linearly rather than logarithmic with coverage.

\section{Pseudo-First-Order Kinetics}

The adsorption data were modeled using the Lagergren pseudo-first-order kinetics given by:

$\log \left(\mathrm{q}_{\mathrm{e}}-\mathrm{q}_{\mathrm{t}}\right)=\frac{\mathrm{K}_{1}}{2.303} \mathrm{t}+\log \mathrm{q}_{\mathrm{e}}$

The model was used to show that the physical adsorption mechanism was responsible for the metals' adsorption on the modified clay material. Where $\mathrm{q}_{\mathrm{e}}$ represents the amount of metal adsorbed at equilibrium, $\mathrm{q}_{\mathrm{t}}\left(\mathrm{mg} \mathrm{g}^{-1} \mathrm{~min}\right)$ represents the amount of metal adsorbed on the surface of the adsorbent at any time $t(\mathrm{~min})$, and $\mathrm{K}_{1}$ $\min ^{-1}$ represents the equilibrium rate constant of pseudofirst-order adsorption kinetics as given by Lagergren [49]. The rate constant $K_{1}$ was determined from the slope of log $\left(\mathrm{q}_{\mathrm{e}}-\mathrm{q}_{\mathrm{t}}\right)$ versus time $\mathrm{t}$ for plots in which straight lines were obtained. An obtained straight-line graph of the plot of $\log \left(\mathrm{q}_{\mathrm{e}}-\mathrm{q}_{\mathrm{t}}\right)$ versus time $\mathrm{t}$ obtained, as well as closeness in values of $\mathrm{q}_{\mathrm{eCal}}$ to $\mathrm{q}_{\mathrm{eExp}}$, suggests the applicability of the model.

The results of this study showed that straight line graphs were obtained for metals' adsorption on the modified clay material as shown in Fig. 11, but the values of $\mathrm{q}_{\mathrm{eCal}}$ were not close to those of $\mathrm{q}_{\mathrm{eExp}}$ as shown in Table 6 . This suggests that the adsorption processes cannot be explained by the pseudo-first-order kinetic model.
Table 5. Temkin isotherm parameters for the modified clay soils

\begin{tabular}{lclcl}
\hline Parameters & $\mathrm{Pb}$ & \multicolumn{1}{c}{$\mathrm{Ni}$} & $\mathrm{Cu}$ & \multicolumn{1}{c}{$\mathrm{Cr}$} \\
\hline $\mathrm{R}^{2}$ & 0.9655 & 0.8927 & 0.9695 & 0.8648 \\
$\mathrm{~B}$ & 52.11 & 3.53 & 26.90 & 1.546 \\
$\mathrm{~b}_{\mathrm{T}}$ & 47.87 & $7.44 \times 10^{2}$ & 92.72 & $1.6 \times 10^{3}$ \\
$\mathrm{~A}_{\mathrm{T}}$ & 0.943 & 1.231 & 0.1551 & 0.591 \\
\hline
\end{tabular}

Table 6. Pseudo-first-order Kinetics parameters for the modified clay

\begin{tabular}{lllll}
\hline Parameters & $\mathrm{Pb}$ & $\mathrm{Ni}$ & $\mathrm{Cu}$ & \multicolumn{1}{c}{$\mathrm{Cr}$} \\
\hline $\mathrm{R}^{2}$ & 0.9033 & 0.5736 & 0.933 & 0.9078 \\
$\mathrm{~K}_{1}$ & 0.1566 & 0.0836 & 0.0083 & 0.0299 \\
$\mathrm{q}_{\text {eExp }}$ & 0.4193 & 1.3424 & 0.2125 & 0.3334 \\
$\mathrm{q}_{\text {eCal }}$ & 0.988 & 0.680 & 0.790 & 0.699 \\
\hline
\end{tabular}

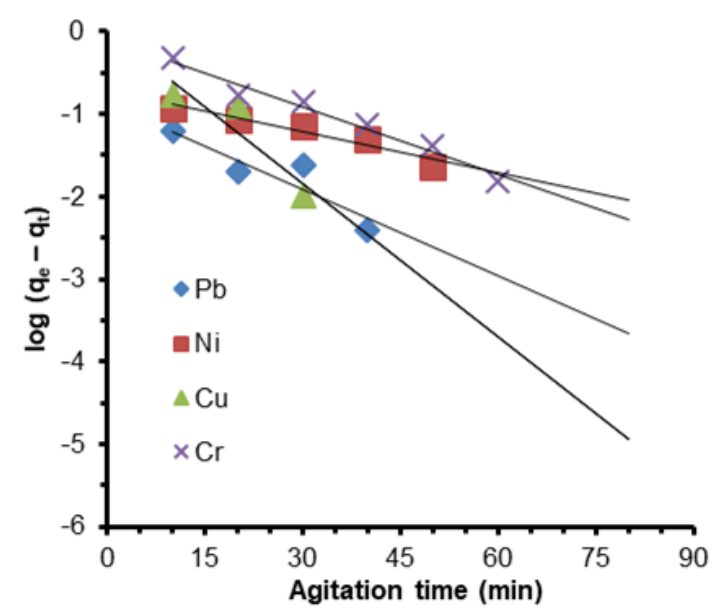

Fig 11. Plot of $\log \left(\mathrm{q}_{\mathrm{e}}-\mathrm{q}_{\mathrm{t}}\right)$ vs. agitation time (min) for modified clay

\section{Pseudo-Second-Order Kinetics}

The linearized form of the Pseudo-second-order kinetics was applied to explain the adsorption processes of the metals on the modified clay material. It is given by:

$\frac{\mathrm{t}}{\mathrm{q}_{\mathrm{t}}}=\frac{1}{\mathrm{~h}}+\frac{\mathrm{t}}{\mathrm{q}_{\mathrm{e}}}$

where $\mathrm{h}=\mathrm{kq}_{\mathrm{e}}^{2}(\mathrm{mg} /(\mathrm{g} \min ))$ [46].

Thus, the pseudo-second-order equation can be written as:

$\frac{\mathrm{t}}{\mathrm{q}_{\mathrm{t}}}=\frac{1}{\mathrm{~K}_{2} \mathrm{q}_{\mathrm{e}}^{2}}+\frac{\mathrm{t}}{\mathrm{q}_{\mathrm{e}}}$

where $\mathrm{k}(\mathrm{g} /(\mathrm{mg} \min ))$ represents the pseudo-secondorder rate constant, $\mathrm{q}_{\mathrm{t}}\left(\mathrm{mg} \mathrm{g}^{-1} \mathrm{~min}\right)$ represents the amount of metal adsorbed on the surface of the 
adsorbent at any time $\mathrm{t}$, while $\mathrm{q}_{\mathrm{e}}\left(\mathrm{mg} \mathrm{g}^{-1}\right)$ represents the amount of metal adsorbed at equilibrium [46].

The values of $\mathrm{q}_{\mathrm{e}}, \mathrm{k}$, and $\mathrm{h}$ were determined experimentally by plotting $t / \mathrm{q}_{\mathrm{t}}$ against $\mathrm{t}$. The Pseudosecond-order kinetic plot of the modified clay is shown in Fig. 12. The values of $\mathrm{q}_{\mathrm{eCal}}$ for the adsorption process of all the metals onto the modified clay correlate to those of $\mathrm{q}_{\text {eexp }}$, as shown in Table 7. This implies that the adsorption process can be explained and represented by pseudosecond-order kinetics. The linear regression $\mathrm{R}^{2}$ values of the pseudo-second-order kinetics for all the metals' adsorption processes are closer to unity than those of the pseudo-first-order plot. This showed that the adsorption processes best fit the pseudo-second-order kinetics. This fitting implies that there is a possible chemical interaction between the adsorbates and adsorbents during the adsorption processes. Hence, the adsorption process is driven by a chemical mechanism.

\section{Elovich Kinetics}

The Elovich equation was applied to test the suitability of the model. Elovich kinetic model shows the extent surface coverage and activation energy of chemisorptions of adsorbates on heterogeneous adsorbing surfaces. The Elovich kinetics was modeled using the linear form of the equation as represented in Eq. (11) [50].

$\mathrm{q}_{\mathrm{t}}=\frac{1}{\beta} \ln (\alpha \beta)+\frac{1}{\beta} \ln (\mathrm{t})$

where $\alpha$ represents the initial adsorption rate $\left(\mathrm{mg} \mathrm{g}^{-1}\right.$ $\mathrm{min}$ ), and $\beta$ is related to the extent of surface coverage and the activation energy for chemisorption $\left(\mathrm{g} \mathrm{mg}^{-1}\right)$. The constants $\alpha$ and $\beta$ were obtained from the slope $\left(\frac{1}{\beta}\right)$ and an intercept $\left[\frac{1}{\beta} \ln (\alpha \beta)\right]$ of the linear plot of $\mathrm{q}_{\mathrm{t}}$ versus $\ln \mathrm{T}$. Elovich kinetic plots are represented by Fig. 13.

Generally, the $\mathrm{R}^{2}$ value is used to show the suitability and applicability of the model. The results from Table 8 showed that the $\mathrm{R}^{2}$ values obtained for adsorption processes are less close to unity than the pseudo-firstorder and pseudo-second-order kinetics. This implies that the adsorption processes cannot be explained by the Elovich kinetic model.

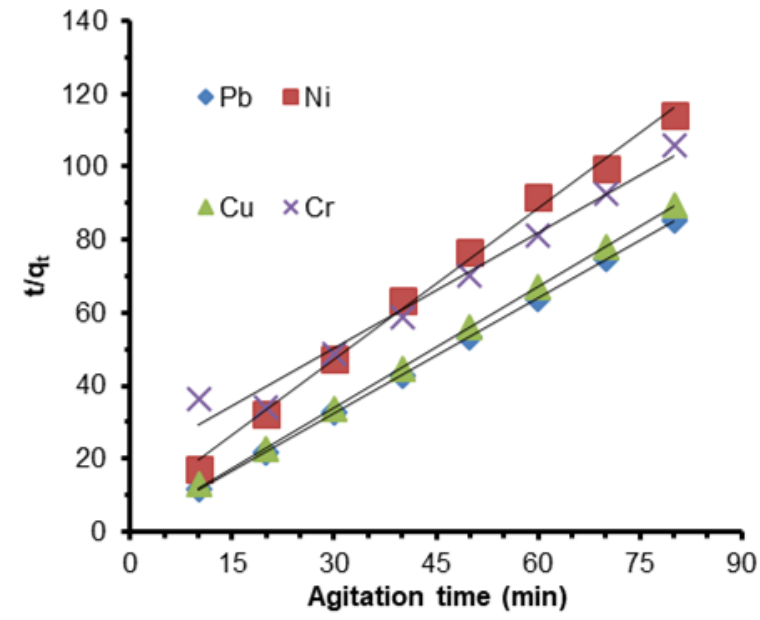

Fig 12. Plot of $t / q_{t}$ vs. agitation time (min) for the modified clay material

Table 7. Pseudo-second-order kinetics parameters for the raw and modified clay soils

\begin{tabular}{cllll}
\hline Parameters & \multicolumn{1}{c}{$\mathrm{Pb}$} & \multicolumn{1}{c}{$\mathrm{Ni}$} & \multicolumn{1}{c}{$\mathrm{Cu}$} & \multicolumn{1}{c}{$\mathrm{Cr}$} \\
\hline $\mathrm{R}^{2}$ & 0.9999 & 0.9952 & 0.9997 & 0.9786 \\
$\mathrm{~K}$ & 1.4286 & 0.3615 & 1.2253 & 0.0950 \\
$\mathrm{q}_{\text {eExp }}$ & 0.948 & 0.7235 & 0.9089 & 0.9067 \\
$\mathrm{q}_{\mathrm{eCal}}$ & 0.938 & 0.702 & 0.895 & 0.755 \\
\hline
\end{tabular}

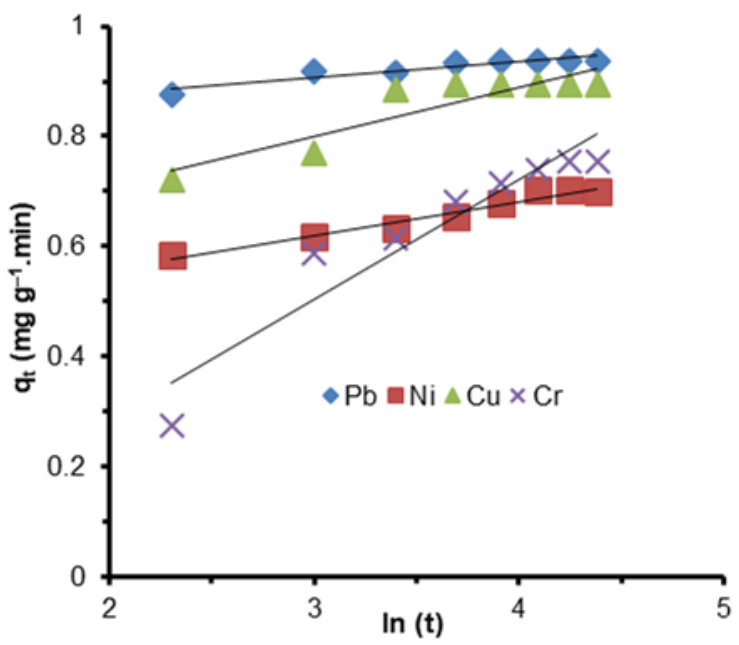

Fig 13. Plot of $\mathrm{q}_{\mathrm{t}}\left(\mathrm{mg} \mathrm{g}^{-1} \mathrm{~min}\right)$ vs. $\ln (\mathrm{t})$ for the modified clay

Table 8. Elovich isotherm parameters for the modified clay material

\begin{tabular}{ccccc}
\hline Parameter & $\mathrm{Pb}$ & $\mathrm{Ni}$ & $\mathrm{Cu}$ & $\mathrm{Cr}$ \\
\hline $\mathrm{R}^{2}$ & 0.8697 & 0.9684 & 0.8249 & 0.9048 \\
\hline
\end{tabular}




\section{- CONCLUSION}

This study has investigated the enhancement of the adsorptive properties of Nigerian clay (Ire-Ekiti clay) for its potential application for the remediation of lead, chromium, nickel, and copper in their respective contaminated aqueous solution. Findings from this study showed that modification of the clay by anionic surfactant sodium dodecyl sulfate improved its heavy metals adsorption properties. The improved properties include pore diameter, pore numbers, exchangeable cations, surface morphology, and available active sites for metal binding. The instrumentations employed for the materials' characterization were able to give sufficient information on the subject matter. The results from the adsorption study showed a fast rate of the metals' removal by the modified clay material, and a very good percentage of the metals were adsorbed. Adsorption efficiency of the modified clay measured in the form of a percentage of metal removed reached the values of $98.5 \%, 94.5 \%, 80.3 \%$, and $73.8 \%$ for the $\mathrm{Pb}, \mathrm{Cu}, \mathrm{Cr}$, and $\mathrm{Ni}$, respectively. The outcome of this research and information contained in this study showed that SDS modified clay is a promising material for remediation of heavy metal contaminated water and laden solution beyond an acceptable level. We recommend that other modification techniques be employed for surface modification of the clay for improved adsorptive properties and efficiency.

\section{REFERENCES}

[1] Awaleh, M.O., and Soubaneh, Y.D., 2014, Waste water treatment in chemical industries: The concept and current technologies, Hydrol.: Curr. Res., 5 (1), 1000164.

[2] Saxena, G., Chandra, R., and Bharagava, R.N., 2016, Environmental pollution, toxicity profile and treatment approaches for tannery wastewater and its chemical pollutants, Rev. Environ. Contam. Toxicol., 240, 31-69.

[3] Wen, J., Fang, Y., and Zeng, G. 2018, Progress and prospect of adsorptive removal of heavy metal ions from aqueous solution using metal-organic frameworks: A review of studies from the last decade, Chemosphere, 201, 627-643.
[4] Chen, C.W., Chen, C.F., and Dong, C.D., 2012, Distribution and accumulation of mercury in sediments of Kaohsiung River mouth, Taiwan, APCBEE Procedia, 1, 153-158.

[5] Ahmaruzzaman, M., 2011, Industrial wastes as lowcost potential adsorbents for the treatment of wastewater laden with heavy metals, Adv. Colloid Interface Sci., 166 (1), 36-59.

[6] Guillaume, P.L.A., Chelaru, A.M., Visa, M., and Lassine, O., 2018, "Titanium oxide-clay" as adsorbent and photocatalysts for wastewater treatment, J. Membrane Sci. Technol., 8 (1), 1000176

[7] Pinto, A.C.S., Grossi, L., de Melo, R.A.C, de Assis, T.M., Ribeiro, V.M., Amaral, M.S.C., and Figueiredo, K.C.S, 2017, Carwash wastewater treatment by micro and ultrafiltration mem-branes: Effects of geometry, pore size, pressure difference and feed flow rate in transport properties, J. Water Process Eng., 17, 143-148.

[8] Tan, J., Huang, Y., Wu, Z., and Chen, X., 2017, Ion exchange resin on treatment of copper and nickel wastewater, IOP Conf. Ser.: Earth Environ. Sci., 94, 012122.

[9] Akhter, M., Habib, G., and Qama, S.U., 2018, Application of electrodialysis in waste water treatment and impact of fouling on process performance, J. Membr. Sci. Technol., 8 (2), 1000182.

[10] Jaishankar, M., Mathew, B.B., Shah, M.S., Murthy, K.T.P., and Gowda, S.K.R., 2014, Biosorption of few heavy metal ions using agricultural wastes, $J$. Environ. Pollut. Hum. Health, 2, 1-6.

[11] Adekeye, D.K., Popoola, O.K., Asaolu, S.S., Adebawore, A.A., Aremu, O.I., and Olabode, K.O., 2019, Adsorption and conventional technologies for environmental remediation and decontamination of heavy metals: an overview, Int. J. Res. Rev., $6(8), 505-516$.

[12] Uddin, M.K., 2016, A review on the adsorption of heavy metals by clay minerals, with special focus on the past decade, Chem. Eng. J., 308, 438-462.

[13] Mustapha, S., Ndamitso, M.M., Abdulkareem, A.S., 
Tijani, J.O., Mohammed, A.K., and Shuaib, D.T., 2019, Potential of using kaolin as a natural adsorbent for the removal of pollutants from tannery wastewater, Heliyon, 5 (11), e02923.

[14] Kumrić, K.R., Đukić, A.B., Trtić-Petrović, T.M., Vukelić, N.S., Stojanović, Z., Novaković, J.D.G., Matović, L., 2013, Simultaneous removal of divalent heavy metals from aqueous solutions using raw and mechanochemically treated interstratified montmorillonite/kaolinite clay, Ind. Eng. Chem. Res., 52 (23), 7930-7939.

[15] Iannicelli-Zubiani, E.M., Cristiani, C., Dotelli, G., and Stampino, G.P. 2017, Recovery of valuable metals from electronic scraps by clays and organoclays: Study on bi-ionic model solutions, Waste Manage., 60, 582.

[16] Fu, F., and Wang, Q., 2011, Removal of heavy metal ions from wastewaters: A review, J. Environ. Manage., 92 (3), 407-418.

[17] Srinivasan, R., 2011, Advances in application of natural clay and its composites in removal of biological, organic, and inorganic contaminants from drinking water, Adv. Mater. Sci. Eng., 2011, 872531.

[18] Adekeye, D.K., Asaolu, S.S., Adefemi, S.O., Ibigbami, O.A., Adebawore, A.A., Osundare, O.S., and Olumide, A.H., 2019, Clay soil modification techniques for the adsorption of heavy metals in aqueous medium: A review, Int. J. Adv. Re. Chem. Sci., 6 (6), 14-31.

[19] Yuan, G.D., Theng, B.K.G., Churchman, G.J., and Gates, W.P., 2013, "Chapter 5.1 - Clays and clay minerals for pollution control" in Development in Clay Science Series: Handbook of Clay Science, $2^{\text {nd }}$ Ed., Eds. Bergaya, F., and Lagaly, G., $2^{\text {nd }}$ Ed., Elsevier, 587-644.

[20] Al-Essa, K., and Khalili, F., 2018, Heavy metals adsorption from aqueous solutions onto unmodified and modified Jordanian kaolinite clay: batch and column techniques, Am. J. Appl. Chem., 6 (1), 25-34.

[21] Akpomie, K.G., Odewole, O.A., Ibeji, C.U., Okagu, O.D., and Agboola., I.I., 2017, Enhanced sorption of trivalent chromium unto novel cassava peel modified kaolinite clay, Der Pharma Chem., 9 (5), 48-55.

[22] Zen, S., El Berrichi, F.Z., Abidi, N., Duplay, J., Jada, A., and Gasmi, B., 2018, Activated kaolin's potential adsorbents for the removal of Derma Blue R67 acid dye: kinetic and thermodynamic studies, Desalin. Water Treat., 112, 196-206.

[23] Marino, T., Russo, F., Rezzouk, L., Bouzid, A., and Figoli, A., 2017, PES-kaolin mixed matrix membranes for arsenic removal from water, Membranes, 7, 57.

[24] Zhu, J., Cozzolino, V., Pigna, M., Huang, Q., Caporale, A.G., and Violante, A., 2011, Sorption of $\mathrm{Cu}, \mathrm{Pb}$ and $\mathrm{Cr}$ on Na-montmorillonite: Competition and effect of major elements, Chemosphere, 84 (4), 484-489.

[25] Olu-Owolabi, B.I., Alabi, A.H., Unuabonah, E.I., Diagboya, P.N., Böhm, L. and Düring, R., 2016, Calcined biomass-modified bentonite clay for removal of aqueous metal ions, J. Environ. Chem. Eng., 4 (1), 1376-1382.

[26] Adekeye, D.K., Asaolu, S.S., Adefemi, S.O., and Ibigbami, O.A., 2019, Heavy metal adsorption properties of the basement complex of clay deposit in Ire-Ekiti Southwestern Nigeria, IOSR J. Environ. Sci. Toxicol. Food Technol., 13 (2), 1-8.

[27] Mbaye, C.A.K., Diop, J.M., Miehe-Brendle, J., Senocq, F., and Maury, F., 2014, Characterization of natural and chemically modified kaolinite from Mako (Senegal) to remove lead from aqueous solutions, Clay Miner., 49 (4), 527-539.

[28] Olagboye, S.A., Ejelonu, B.C., Oyeneyin, O.E., Adekeye, D.K., and Gbolagade, Y.A., 2018, Synthesis, characterization and antimicrobial activities of metal complexes of $\mathrm{Cu}$ (II) and $\mathrm{Zn}$ (II) with prednisolone in water-isopropyl alcohol medium, Int. J. Adv. Res. Chem. Sci., 5(12), 16-23.

[29] Akinola, Oluwatoyin, O., Ademilua, and Oladimeji, L., 2014, Compositional features and functional industrial applications of the lateritic clay deposits in Oye-Ekiti and Environs, Southwestern Nigeria, IJST, 2 (9), 6-12. 
[30] Awokunmi, E.E., and Asaolu, S.S., 2017, Physicochemical and performance evaluation of natural and modified Ire-Ekiti clay: Emerging substrate in the de-fluoridation of drinking water, $J$. Phys. Chem. Sci., 5 (4), 1-5.

[31] Cristiani, C., Iannicelli-Zubiani, E.M., Bellotto, M., Dotelli, G., Stampino, P.G., Latorrata, S., Ramis, G., and Finocchio, E, 2021, Capture mechanism of La and $\mathrm{Cu}$ ions in mixed solutions by clay and organoclay, Ind. Eng. Chem. Res., 60 (18), 6803-6813.

[32] Erdemoğlu, M., Erdemoğlu, S., Sayilkan, F., Akarsu, M., Şener, S., and Sayilkan, H., 2004, Organofunctional modified pyrophyllite: Preparation, characterization and $\mathrm{Pb}(\mathrm{II})$ ion adsorption property, Appl. Clay Sci., 27 (1), 41-52.

[33] Chaari, I., Medhioub, M., and Jamaoussi, F., 2011, Use of clay to remove heavy metals from Jebel Chakir landfill leachate, J. Appl. Sci. Environ. Sanit., 6 (2), 143-148.

[34] Dal Bosco, S.M., Jimenez R.S., Vignado, C., Fontana, J., Geraldo, B. Figueiredo, F.C.A., Mandelli, D., and Carvalho, W.A., 2006, Removal of Mn(II) and Cd(II) from wastewaters by natural and modified clays, Adsorption, 12 (2), 133-146.

[35] Jaiswal, A., Banerjee, S., Mani, R., and Chattopadhyaya, M.C., 2013, Synthesis, characterization and application of goethite mineral as an adsorbent, J. Environ. Chem. Eng., 1 (3), 281289.

[36] Senthil, K.P., Vincent, C.K., Kirthika, K., and Sathish, K.K., 2010, Kinetics and equilibrium studies of $\mathrm{Pb}^{2+}$ ion removal from aqueous solutions by use of nanosilversol-coated activated carbon, Braz. J. Chem. Eng., 27 (2), 339-346.

[37] Teixeira, S.C.G., Ziolli, R.L., Marques, M.R.C., and Pérez, D.V., 2011, Study of pyrene adsorption on two Brazilian soils, Water Air Soil Pollut., 219 (1), 297301.

[38] An, C., Huang, G., Yu, H., Wei, J., Chen, W., and Li, G., 2010, Effect of short-chain organic acidsn and $\mathrm{pH}$ on the behaviors of pyrene in soil-water system, Chemosphere, 81, 1423-1429.
[39] Olu-Owolabi, B.I., Diagboya, P.N., and Adebowale, K.O., 2014, Evaluation of pyrene sorptiondesorption on tropical soils, J. Environ. Manage., 137, 1-9.

[40] Rattanaphani, S., Chairat, M., Bremner, J.B., and Rattanaphani, V., 2007, An adsorption and thermodynamic study of lac dyeing on cotton pretreated with chitosan, Dyes Pigm., 72 (1), 88-96.

[41] Zouraibi, M., Ammuri, A., Khadija, Z., and Saidi, M., 2016, Adsorption of $\mathrm{Cu}(\mathrm{II})$ onto natural clay: Equilibrium and thermodynamic studies, J. Mater. Environ. Sci., 7 (2), 566-570.

[42] Kara, S., Aydiner, C., Demirbas, E., Kobya, M., and Dizge, N., 2007, Modeling the effects of adsorbent dose and particle size on the adsorption of reactive textile dyes by fly ash, Desalination, 212 (1), 282-293.

[43] Langmuir, I., 1918, The adsorption of gases on plane surfaces of glass, mica and platinum, J. Am. Chem. Soc., 40 (9), 1361-1403.

[44] Freundlich, H.M.F., 1906, Over the adsorption in solution, J. Phys. Chem., 57, 385-471.

[45] Ramachandran, P., Vairamuthu, R., and Ponnusamy, S., 2011, Adsorption isotherms, kinetics, thermodynamics and desorption studies of Reactive Orange 16 on activated carbon derived from Ananas Comosus (L.) carbon, ARPN J. Eng. Appl. Sci., 6 (11), 15-26.

[46] Asaolu, S.S., Adefemi, S.O., Ibigbami, O.A., and Adekeye, D.K., 2020, Kinetics, isotherm and thermodynamic properties of the basement complex of clay deposit in Ire-Ekiti Southwestern Nigeria for heavy metals removal, Nat. Environ. Pollut. Technol., 19 (3), 897-907.

[47] De la Rosa, G., Reynel-Avila, H.E., BonillaPetriciolet, A., Cano-Rodríguez, I., Velasco-Santos, C., and Martínez-Hernández, A.L., 2008, Recycling poultry feathers for $\mathrm{Pb}$ removal from wastewater: Kinetic and equilibrium studies, Int. J. Chem. Mol. Eng., 2 (11), 338-346.

[48] Temkin, M.I., and Pyzhev, V., 1940, Kinetics of ammonia synthesis on promoted iron catalyst, Acta Physicochim. URSS, 12, 327-356. 
[49] Lagergren, S., 1898, Zur theorie der sogenannten adsorption gelöster stoffe (About the theory of socalled adsorption of soluble substances), K. Sven. Vetensk.Akad. Handl., 24, 1-39.
[50] Roginsky, S.Z., and Zeldovich, J., 1934, An equation for the kinetics of activated adsorption, Acta Physicochim. URSS, 1, 554-559. 